\title{
High magnetomechanical coupling on magnetic microwire for sensors with biological applications
}

\author{
P. Marín,, ${ }^{a)}$ M. Marcos, and A. Hernando \\ Departamento de Física de Materiales, Instituto de Magnetismo Aplicado, UCM-ADIF-CSIC, UCM, \\ P.O. Box 155, Las Rozas, Madrid 28230, Spain
}

(Received 1 June 2010; accepted 11 June 2010; published online 2 July 2010)

\begin{abstract}
In this letter, we report the experimental work carried out to study and improve the magnetomechanical coupling on magnetic microwires. A good magnetoelastic response, with magnetoelastic coupling factor $\mathrm{k}=0.43$, has been obtained by control of both wire diameter and sample microstructure. The study addresses two following aspects: (a) analysis of the suitability of amorphous magnetoelastic microwire as promising tiny sensor element to be used as wireless biosensors as well as environment detectors. In particular, its potential as liquids viscosity sensor has been confirmed. (b) Study, as the first time in this kind of magnetic microwire, of the effects of nanocrystallization on the sample magnetoelastic behavior. (C) 2010 American Institute of Physics. [doi:10.1063/1.3459140]
\end{abstract}

The development of wireless sensors and biosensors is a topic of great current interest. ${ }^{1}$ Due to its magnetoelastic nature, amorphous magnetostrictive alloys exhibit a mechanical resonance when exposed to a time-varying magnetic field. The frequency, amplitude, and damping of the vibration give information of the sensor environment.

The magnetoelastic resonance can be monitored by using a pickup coil without the use of direct physical contacts. Because of this unique advantage, numerous applications have been proposed for the ribbon shaped alloys, including the detection of $p \mathrm{H}^{2}, \mathrm{CO}_{2},{ }^{3}$ pressure, ${ }^{4}$ humidity, ${ }^{5}$ viscosity, ${ }^{6}$ stress, etc. Some kind of biosensors have been also developed using ribbons for the detection of Salmonella typhimurium. ${ }^{7-9}$ On the other hand, amorphous magnetic microwires obtained by Taylor technique, ${ }^{10}$ have been thoroughly studied due to its interesting magnetic properties and their promising applications. ${ }^{11}$ The research in this kind of materials has been mainly focused on magnetic bistability, ${ }^{12,13}$ giant magnetoimpedance effect, ${ }^{14}$ and ferromagnetic resonance ${ }^{15}$ but no much effort has been devoted to the magnetoelastic resonance of these materials. Its small dimensions and its pyrex coating make them optimal candidates for the development of wireless sensors and biosensors. Other authors have analyzed the influence of nanocrystalline microstructure on magnetoelastic behavior of amorphous ribbons ${ }^{16}$ confirming an improvement of the coupling factor of $30 \%$. $^{17,18}$

The aim of the present work is to analyze in detail the magnetoelastic resonance of magnetostrictive glass coated microwires. With this purpose, the magnetomechanical coupling factor, $\mathrm{k}$, has been measured as a function of longitudinal bias field. Experiments were performed by using a resonance technique in which the complex susceptibility was measured as a function of frequency. ${ }^{19,20}$ Sample immersion in ethanol, oil, and petrol allowed us to quantify the influence of medium viscosity on the coupling factor, $\mathrm{k}$, and resonance frequency. The influence of the sample microstructure on the magnetoelastic behavior has been also studied.

\footnotetext{
a) Author to whom correspondence should be addressed. Electronic mail: pmarin@adif.es.
}

A rapidly solidified $\mathrm{Fe}_{73} \mathrm{Si}_{11} \mathrm{~B}_{13} \mathrm{Nb}_{3}$ glass-coated amorphous magnetic microwire, with total diameter of $100 \mu \mathrm{m}$, obtained by Taylor technique was annealed for $2 \mathrm{~h}$ between 523 and $783 \mathrm{~K}$ in argon atmosphere. The study was carried out on $3.9 \mathrm{~cm}$ long straight microwires. The hysteresis loops were obtained by a conventional $10 \mathrm{~Hz}$ induction technique. Differential scanning calorimetry has been used to analyze sample crystallization dynamic and to obtain amorphous percentage present in annealed samples. These experiments were carried out in a differential scanning calorimeter Perkin-Elmer DSC 7 operating at a $20 \mathrm{~K} / \mathrm{min}$ fixed scanning rate. Measurements of the resonance frequency have been performed by using a magnetoelastic resonance analyzer set up. Magnetic microwire is inserted in a sample holder containing a liquid (ethanol, oil, or petrol) that is placed inside a pick-up coil. The variation in the coil impedance with frequency allows the observation of resonance, $\nu_{\mathrm{r}}$, and antiresonance, $\nu_{\mathrm{a}}$, frequencies of the microwire. The dc bias field, varying between $4.5-2200 \mathrm{~A} / \mathrm{m}$, was produced by a Helmholtz coils system. The magnetoelastic coupling coefficient, $\mathrm{k}$, has been calculated from the difference between the maximum and minimum admittance values that corresponds to the antiresonance and resonance peaks, respectively, ${ }^{21}$ according to

$$
k=\sqrt{\frac{\pi^{2}}{8}\left[1-\left(\frac{v_{r}}{v_{a}}\right)^{2}\right]} .
$$

This coefficient measures the capability of the material to transfer elastic into magnetic energy and vice versa. ${ }^{22,23}$

Due to the dissipative character of the associated friction shear forces, ${ }^{24}$ the resonant frequency of the microwire shifts, when immersed in a liquid, as a function of viscosity according to

$$
\Delta v=-\frac{\sqrt{\pi v}}{2 \pi \rho d}\left(\eta \rho_{l}\right)^{1 / 2},
$$

where $d$ is the thickness of the sensor, $\eta$ and $\rho_{1}$ are the liquid viscosity and density, respectively. The functional dependence of $\Delta v$ is the same as that for the liquid phase theories of acoustic wave quartz sensors. ${ }^{25}$ 


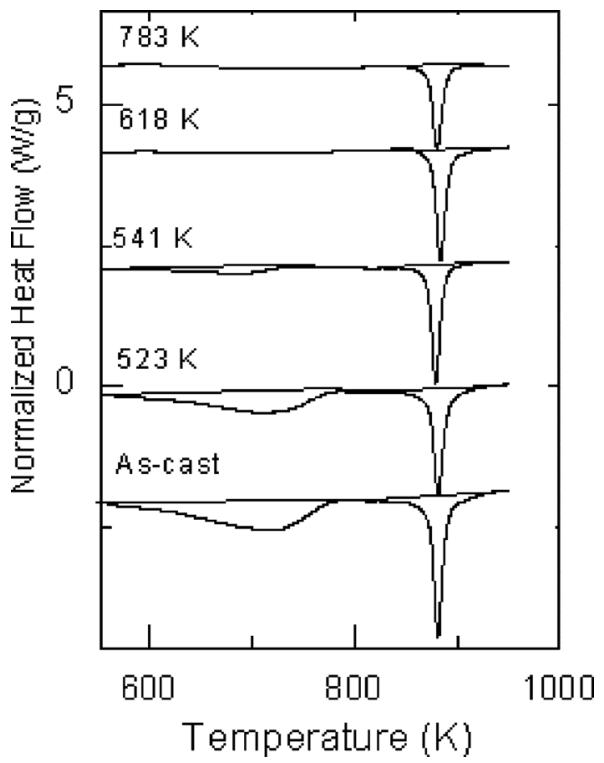

FIG. 1. Evolution of differential scanning calorimetric plots with annealing temperature for $\mathrm{Fe}_{73} \mathrm{Si}_{11} \mathrm{~B}_{13} \mathrm{Nb}_{3}$ glass-coated amorphous magnetic microwire.

The structural evolution of the as-cast $\mathrm{Fe}_{73} \mathrm{Si}_{11} \mathrm{~B}_{13} \mathrm{Nb}_{3}$ microwire induced by the increase in temperature is shown in the calorimetric curve of Fig. 1. Two exothermic peaks at $\mathrm{T}_{\mathrm{x} 1}=718$ and $\mathrm{T}_{\mathrm{x} 2}=883 \mathrm{~K}$ are observed. This plot also shows the influence of pre-annealing temperature, between 523 and $783 \mathrm{~K}$, on the shape of the DSC curve and the crystallization temperatures, $\mathrm{T}_{\mathrm{x} 1}$ and $\mathrm{T}_{\mathrm{x} 2}$. The changes induced by preannealing on the crystallization enthalpies, $\Delta \mathrm{H}_{\mathrm{x}}$, is also shown in Table I. From this data it can be confirmed that the structural rearrangements induced for annealing temperatures of 541 and $783 \mathrm{~K}$ result in a decrease in the crystallization enthalpy. However, complete nanocrystallization occurs for annealing temperatures above $783 \mathrm{~K}$ [see Fig. 2(d) and Table I]. In consequence the enthalpy energy decrease, observed after annealing at low temperatures, should be ascribed to the initial stages of nanocrystallization process.

The strength of the magnetomechanical coupling depends upon the ease of rotation of magnetization. For large coupling mainly high susceptibility rotational magnetization is required. ${ }^{20}$ In the case of iron based amorphous ribbons high magnetoelastic coupling factors have been obtained by means of annealing in the presence of magnetic field perpendicular to ribbon axis that induces a transverse homogeneous easy axis. ${ }^{19}$ This procedure cannot be easily carried out in amorphous microwires. However, controlling the nanocrystalline fraction in the amorphous structure allows us to tailor the longitudinal susceptibility of microwires. ${ }^{26,27}$ Hysteresis loops in Fig. 2 show the consequences of crystalline percentage content on microwire magnetic behavior. For the case of

TABLE I. Crystallization temperatures, $\mathrm{T}_{\mathrm{x} 1}$ and $\mathrm{T}_{\mathrm{x} 2}$, and corresponding enthalpies, $\mathrm{E}_{1}$ and $\mathrm{E}_{2}$, for as-cast and annealed microwires.

\begin{tabular}{lcccc}
\hline \hline & $\mathrm{T}_{\mathrm{x} 1}(\mathrm{~K})$ & $\mathrm{T}_{\mathrm{x} 2}(\mathrm{~K})$ & $\mathrm{E}_{1}(\mathrm{~J} / \mathrm{g})$ & $\mathrm{E}_{2}(\mathrm{~J} / \mathrm{g})$ \\
\hline As Cast & 719 & 882 & 117 & 86 \\
$523 \mathrm{~K}$ & 723 & 882 & 80 & 84 \\
$541 \mathrm{~K}$ & 703 & 884 & 29 & 86 \\
$618 \mathrm{~K}$ & 689 & 879 & & 75 \\
$783 \mathrm{~K}$ & 701 & 881 & & 56
\end{tabular}

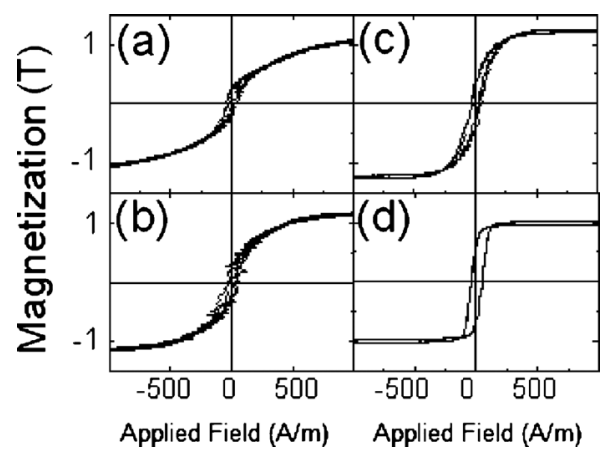

FIG. 2. Influence annealing temperature on $\mathrm{Fe}_{73} \mathrm{Si}_{11} \mathrm{~B}_{13} \mathrm{Nb}_{3}$ glass-coated amorphous magnetic microwire hysteresis loop: as-cast (a), $541 \mathrm{~K}$ (b), 618 $\mathrm{K}(\mathrm{c})$, and $783 \mathrm{~K}(\mathrm{~d})$.

sample annealed at $618 \mathrm{~K}$, a transversal anisotropy with field $\mathrm{H}_{\mathrm{k}}$ of $280 \mathrm{~A} / \mathrm{m}$ is observed, whereas for samples with higher percentage of crystallization (as is the case for that annealed at $783 \mathrm{~K}$ ) a clear decrease of transversal anisotropy associated with a slightly higher coercivity is found. Some previous works in wires ${ }^{26}$ reveal a decrease in longitudinal anisotropy during the first stages of nanocrystallization process. The presence of small grains or crystalline clusters gives rise to an increase in the magnetostriction constant that tends to orientate the domains structure perpendicular to the axial direction resulting in a decrease in microwire longitudinal anisotropy.

Figure 3(a) shows the influence of various isothermal heat treatments on the resonance frequency $\left(\nu_{\mathrm{r}}\right)$ versus magnetic applied field $\left(\mathrm{H}_{\mathrm{o}}\right)$. Figure 3(b) illustrates the same annealing influence but on magnetoelastic coupling factor, $\mathrm{k}$. The maximum range of frequency variation with applied field is observed for the sample annealed at $618 \mathrm{~K}$. In this case the minimum resonance frequency obtained is of 51 $\mathrm{kHz}$ corresponding to the highest coupling factor of 0.43 . It has been reported by Livingston ${ }^{28}$ that the magnetomechani-

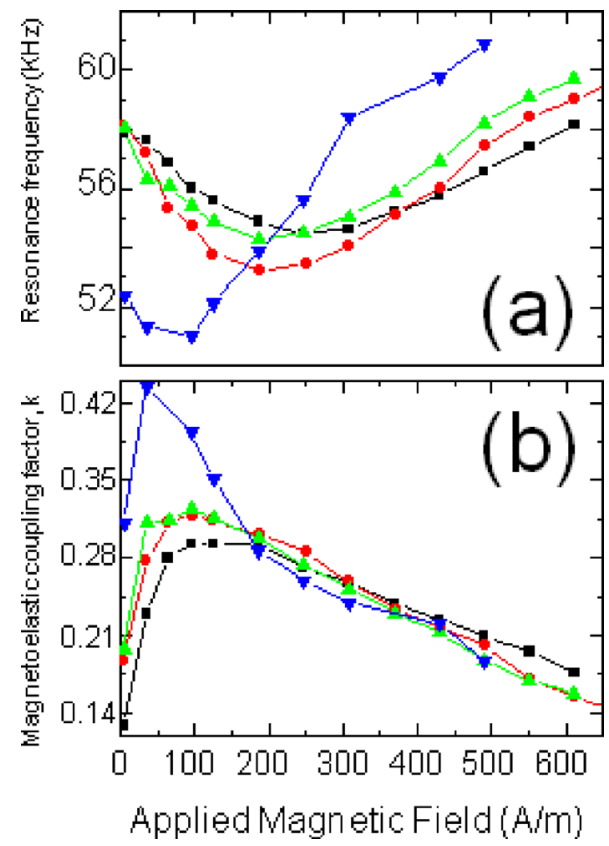

FIG. 3. (Color online) Influence of annealing temperature on magnetoelastic coupling factor (a) and on resonance frequency (b) vs applied field; as-cast $(\boldsymbol{\square}), 523 \mathrm{~K}(\bullet), 541 \mathrm{~K}(\boldsymbol{\Delta})$, and $618 \mathrm{~K}(\mathbf{\nabla})$ for $\mathrm{Fe}_{73} \mathrm{Si}_{11} \mathrm{~B}_{13} \mathrm{Nb}_{3}$ glass-coated amorphous magnetic micrewire tion. aip.org/termsconditions. Downloaded to IP 


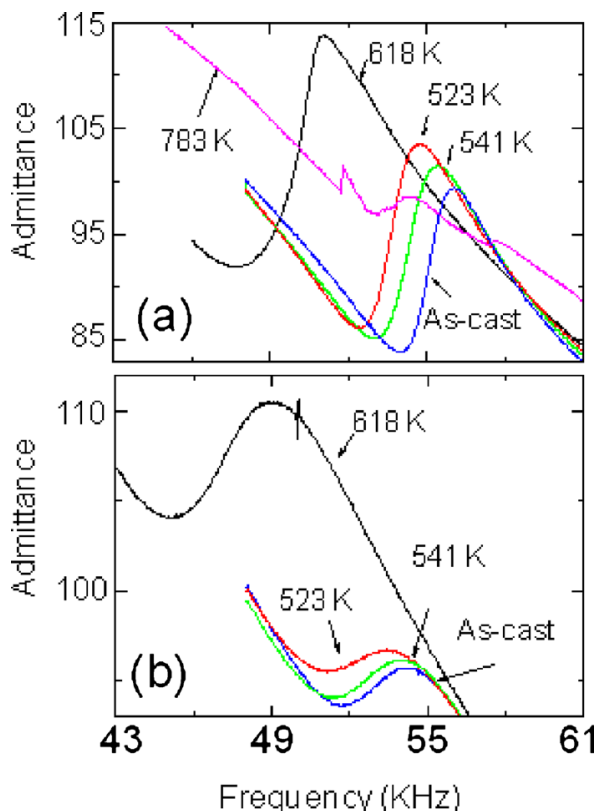

FIG. 4. (Color online) Influence of annealing temperature on resonance curves of $\mathrm{Fe}_{73} \mathrm{Si}_{11} \mathrm{~B}_{13} \mathrm{Nb}_{3}$ glass-coated amorphous magnetic microwire measured with a $96 \mathrm{~A} / \mathrm{m}$ bias field; in ethanol (a) and oil (b).

cal coupling reaches a maximum value when the bias field takes the value of the transverse induced anisotropy field. Two kinds of measurements, using ethanol and oil have been performed and compared. Figure 4 displays the frequency dependent response of as-cast and annealed wires in both liquids, respectively, measured at room temperature and for a bias field of $96 \mathrm{~A} / \mathrm{m}$. As has been previously said the nanocrystalline content of the samples remarkably influences the microwire response. When annealing temperature is below $541 \mathrm{~K}$ resonance peak frequency is slightly displaced from that of the as-cast sample but the effect is much more evident for the sample annealed at $618 \mathrm{~K}$ where a decrease of around $4 \mathrm{KHz}$ associated with an increase in signal level is observed. This tendency is confirmed in both liquids being observed a damping in the case of oil.

In order to confirm the reliability of the $618 \mathrm{~K}$ annealed microwire as sensor element the response has been also analyzed when using petrol as a third liquid. Figure 5 compares the behavior of the nanocrystallized wire using $96 \mathrm{~A} / \mathrm{m}$ as bias field.

In summary, amorphous magnetoelastic microwire has been appropriately casted to be used as sensor element in wireless sensors and biosensors. Large magnetoelastic coupling factor has been obtained in samples annealed at tem-

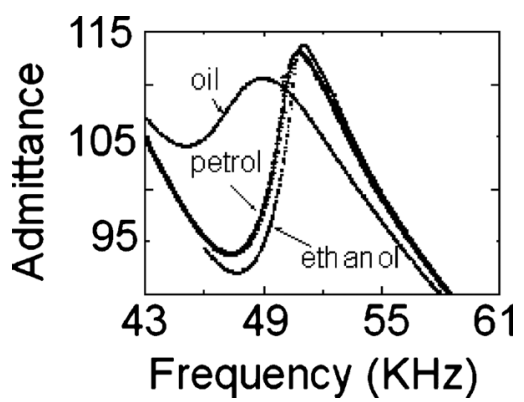

FIG. 5. Resonance curves of $\mathrm{Fe}_{73} \mathrm{Si}_{11} \mathrm{~B}_{13} \mathrm{Nb}_{3}$ glass-coated amorphous magnetic microwire annealed at $618 \mathrm{~K}$ amorphous measured in the presence of a bias field of $96 \mathrm{~A} / \mathrm{m}$ in ethanol $(\mathbf{\square})$, oil $(\bigcirc)$, and petrol $(\mathbf{\Lambda})$. peratures corresponding to the range of initial stages of nanocrystallization process. The proposed microwire of composition $\mathrm{Fe}_{73} \mathrm{Si}_{11} \mathrm{~B}_{13} \mathrm{Nb}_{3}$ and diameter $100 \mu \mathrm{m}$ has been annealed at $618 \mathrm{~K}$ and presents magnetoelastic coupling factor $\mathrm{k}=0.43$, when immersed in ethanol and for a bias applied field of $50 \mathrm{~A} / \mathrm{m}$. The sensitivity of this wire has been tested, also in oil and petrol. The experimental results are promising for future developments in this field including in situ and in vivo magnetoelastic experiments, until now only possible by using magnetic ribbons. ${ }^{29,30}$

Authors want to acknowledge Micromag 2000, S.L. for microwire supply and Professor G. Rivero for his interesting contributions during discussions. This work has been supported by the MEC of Spain (Contract Nos. CSD2007-0010 and MAT2009-14741-C02-01).

${ }^{1}$ M. V. Voinova, Journal of Sensors 2009, 943125 (2009).

${ }^{2}$ Q. Y. Cai and C. A. Grimes, Sens. Actuators B 71, 112 (2000).

${ }^{3}$ Q. Y. Cai, A. Cammers-Goodwin, and C. A. Grimes, J. Environ. Monit. 2, 556 (2000).

${ }^{4}$ C. A. Grimes and D. Kouzoudis, Sens. Actuators, A 84, 205 (2000).

${ }^{5}$ M. K. Jain, S. Schmidt, K. G. Ong, C. Mungle, and C. A. Grimes, Smart Mater. Struct. 9, 502 (2000).

${ }^{6}$ C. A. Grimes, D. Kouzoudis, and C. Mungle, Rev. Sci. Instrum. 71, 3822 (2000).

${ }^{7}$ R. Guntupalli, J. Hu, R. S. Lakshamanan, T. S. Huang, J. M. Barbaree, and B. Chin, Biosens. Bioelectron. 22, 1474 (2007).

${ }^{8}$ R. Guntupalli, R. S. Lakshmanan, J. Hua, T. S. Huang, J. M. Barbaree, V. Vodyanoy, and B. A. Chin, J. Microbiol. Methods 70, 112 (2007).

${ }^{9}$ P. Pang, S. Huang, Q. Cai, S. Yao, K. Zeng, and C. A. Grimes, Biosens. Bioelectron. 23, 295 (2007).

${ }^{10}$ G. F. Taylor, Phys. Rev. 24, 655 (1924).

${ }^{11} \mathrm{P}$. Marín and A. Hernando, Encyclopedia of Materials: Science and Technology (Elsevier, Amsterdam, The Netherlands, 2004), pp. 1-9.

${ }^{12}$ M. Vázquez and D. X. Chen, IEEE Trans. Magn. 31, 1229 (1995).

${ }^{13}$ M. Vázquez, C. Gómez-Polo, D. X. Chen, and A. Hernando, IEEE Trans. Magn. 30, 907 (1994).

${ }^{14}$ M. Vázquez, A. P. Zhukov, P. Aragoneses, J. Arcas, J. M. GarciaBeneytez, P. Marín, and A. Hernando, IEEE Trans. Magn. 34, 724 (1998).

${ }^{15}$ A. N. Antonenko, S. A. Baranov, V. S. Larin, and A. V. Torkunov, J. Mater. Sci. Eng. 247, 248 (1997).

${ }^{16}$ P. Mínguez, H. A. Davies, I. Todd, M. R. J. Gibbs, A. García-Arribas, and J. Gutiérrez, J. Non-Cryst. Solids 287, 428 (2001).

${ }^{17}$ P. Marín, M. López, P. Agudo, M. Vázquez, and A. Hernando, Sens. Actuators, A 91, 218 (2001).

${ }^{18}$ L. Lanotte, G. Ausanio, M. Carbucicchio, V. Iannotti, and M. Muller, J. Magn. Magn. Mater. 215-216, 276 (2000).

${ }^{19}$ H. T. Savage, A. E. Clark, and J. M. Powers, IEEE Trans. Magn. 11, 1355 (1975)

${ }^{20}$ C. Modzelewski, H. T. Savage, L. T. Kabacoff, and A. E. Clark, IEEE Trans. Magn. 17, 2837 (1981)

${ }^{21}$ L. T. Kabacoff and M. Wun-Fogle, J. Appl. Phys. 57, 3499 (1985); S. Schmidt and C. A. Grimes, Sens. Actuators, A 94, 189 (2001).

${ }^{22}$ H. T. Savage and R. Abbundi, IEEE Trans. Magn. 14, 545 (1978).

${ }^{23}$ A. Hernando, V. Madurga, J. M. Barandiarán, and M. Linniers, J. Magn. Magn. Mater. 28, 109 (1982); A. Hernando, A. García-Escorial, E. Ascasibar, and M. Vázquez, J. Phys. D: Appl. Phys. 16, 1999 (1983).

${ }^{24}$ C. A. Grimes, K. G. Ong, K. Loiselle, P. G. Stoyanov, D. Kouzoudis, Y. Liu, C. Tong, and F. Tefiku, Smart Mater. Struct. 8, 639 (1999).

${ }^{25}$ K. K. Kanazawa and J. G. Gordon, Anal. Chim. Acta 175, 99 (1985).

${ }^{26}$ M. Vázquez, P. Marín, H. A. Davies, and A. O. Olofinjana, Appl. Phys. Lett. 64, 3184 (1994).

${ }^{27}$ C. Gómez-Polo, D. Holzer, M. Multigner, E. Navarro, P. Agudo, A. Hernando, M. Vázquez, H. Sassik, and R. Grossinger, Phys. Rev. B 53, 3392 (1996).

${ }^{28}$ J. D. Livingston, Phys. Status Solidi A 70, 591 (1982).

${ }^{29}$ P. G. Stoyanov and C. A. Grimes, Sens. Actuators, A 80, 8 (2000)

${ }^{30}$ S. Wu, X. Gao, Q. Cai, and C. Grimes, Sens. Actuators B 123, 856 (2007) 